\title{
Characteristics for Quality of Life during the Clinical Course of Interstitial Lung Disease
}

\author{
Fujiko Someya $^{1^{*}}$, Takao Nakagawa ${ }^{1}$ and Naoki Mugii ${ }^{2}$ \\ ${ }^{1}$ School of Health Sciences, Kanazawa University, Kanazawa, Japan \\ ${ }^{2}$ Division of Rehabilitation Medicine, Kanazawa University Hospital, Kanazawa, Japan
}

\begin{abstract}
Objective: Temporary improvement in health status after available therapy or medication has been reported for interstitial lung disease. However, interstitial lung disease is progressive, and there is no study on the change in quality of life over time. Therefore, we examined the time course of the Chronic obstructive pulmonary disease Assessment Test (CAT) score in relation with pulmonary function and exercise capacity.
\end{abstract}

Methods: Out of 162 subjects with interstitial lung disease, 56 subjects evaluated more than twice by the CAT were assigned retrospectively to the study and divided into two groups according to the duration from disease onset. The percent of predicted forced vital capacity and diffusion capacity of the lung for carbon monoxide, and 6-min walk distance were also collected from the hospital records for analysis.

Results: The CAT score improved in 21 subjects with less than five years of disease ( 15 to $7, p=0.004$ ), but declined in 35 subjects with five or more years (12 to $17, p=0.002)$. The intervals of evaluation were not different between the groups ( 21 and 20 months on average, $p=0.80)$. Forced vital capacity and diffusion capacity of the lung for carbon monoxide at baseline were more impaired in the subjects with longer disease history $(p=0.001$ and $p=0.006$, respectively). The CAT score and diffusion capacity of the lung for carbon monoxide or 6-min walk distance were correlated in each group at the baseline. Pulmonary function declined on repeated evaluation even in subjects with less than five years of disease history.

Conclusion: Quality of life might be improved within five years of disease regardless of deterioration in pulmonary function; however, the improvement would become difficult afterward due to progressive change in pulmonary function or exercise capacity in interstitial lung disease.

Keywords: Health status; Questionnaire; Pulmonary function; 6-min walk test; Interstitial lung disease; Connective tissue disease; Idiopathic interstitial pneumonia

\section{Introduction}

Although some available therapies for interstitial lung disease temporarily relieve the respiratory symptoms, the disease is progressive. Questionnaires for chronic lung disease have been developed to evaluate the symptoms and the Chronic obstructive pulmonary disease Assessment Test (CAT) [1] has been adapted for interstitial lung disease [2]. Cross-sectional studies reported the relationship between the CAT score and the results of pulmonary function tests for interstitial lung disease, and found that higher CAT scores and/ or lower diffusion capacity of the lungs for carbon monoxide $\left(\mathrm{D}_{\mathrm{LCO}}\right)$ significantly predicted mortality $[3,4]$.

Palliative care was recommended for managing symptoms using a multidisciplinary approach including patient education and selfmanagement [5]. For example, dyspnea is the major symptom reported by patients with interstitial lung disease, and it may be ameliorated by pulmonary rehabilitation as well as improvement in exercise capacity as assessed by the 6-min walk test (6MWT) [6-8]. However, it should be noted that patients with severe dyspnea, such as Medical Research Council (MRC) grade 4 or 5, did not improve after pulmonary rehabilitation [7], whereas patients with a good 6MWT distance at baseline were predicted to have a smaller improvement [8,9]. These results suggested that intervention for patients should be conducted during the proper period of the disease. For this purpose, it is important to clarify the characteristics related with quality of life for interstitial lung disease throughout the clinical course.

The CAT is a simple questionnaire comprising eight items that does not require special equipment to evaluate the health status of patients.
The total score ranges from 0 to 40 , with higher scores indicating a poorer health status. It has finer scoring than the classification numbers of the mMRC, which is the most popular evaluation for dyspnea. Therefore, the CAT may be a convenient tool for clinical practice to evaluate the variation in individuals. As we have routinely examined patients with interstitial lung disease using the CAT, the aim of this study was to monitor the time course of the CAT score in relation with pulmonary function and exercise capacity.

\section{Method}

The use of subject records for this study was approved by the Human Ethics Committee of Kanazawa University, conforming to the provisions of the Declaration of Helsinki. As the study was performed retrospectively, written informed consent for participation in the study was not obtained from subjects, but the study was publicly announced online and a notice was placed in our hospital for opt-out. The subject records were anonymized prior to analysis.

One hundred and sixty-two subjects with interstitial lung disease were transferred to the Division of Rehabilitation Medicine, Kanazawa

${ }^{*}$ Corresponding author: Fujiko Someya, School of Health Sciences, Kanazawa University, Kodatsuno 5-11-80, Kanazawa, Japan, Tel: 81762652624; Fax 81762344375; E-mail: fujiko@mhs.mp.kanazawa-u.ac.jp

Received October 30, 2017; Accepted November 02, 2017; Published November 08, 2017

Citation: Someya F, Nakagawa T, Mugii N (2017) Characteristics for Quality of Life during the Clinical Course of Interstitial Lung Disease. J Pulm Respir Med 7: 427 doi: 10.4172/2161-105X.1000427

Copyright: @ 2017 Someya F, et al. This is an open-access article distributed under the terms of the Creative Commons Attribution License, which permits unrestricted use, distribution, and reproduction in any medium, provided the original author and source are credited. 
University Hospital between January 2013 and August 2017 for routine evaluation or treatment. Interstitial lung disease was diagnosed by specialists of respiratory medicine using high-resolution computed tomography. As the CAT was developed in 2009 [1] and translated into Japanese in 2012 [10], follow-up over five years with the CAT was not possible. Due to this limitation, this study was conducted to evaluate the clinical course within four years. The subjects were divided into two groups according to the duration from disease onset to the date of the first evaluation with the CAT; group with disease duration less than five years (early group, $\mathrm{n}=80$ ) and group with longer disease history (late group, $\mathrm{n}=82$ ). Of the total 162 subjects, those evaluated more than twice with the CAT were selected to examine the variations in individual courses. The percent of predicted forced vital capacity (FVC) and $\mathrm{D}_{\mathrm{LCO}}$, and $6 \mathrm{MWT}$ distance were also collected from the hospital records for analysis. Consequently, 56 who were re-evaluated with intervals of more than three months were assigned to the study; 21 subjects were in the early group and 35 subjects were in the late group (Table 1). Evaluation during acute exacerbation was excluded from the study to demonstrate the response of usual clinical care. Unfortunately, 8 in the early group and 14 in the late group were not evaluated for pulmonary function at the time of re-evaluation with the CAT.

\section{Statistics}

Baseline clinical characteristics, including percent of predicted FVC and $\mathrm{D}_{\mathrm{LCO}}$, and $6 \mathrm{MWT}$ distance, were compared between the two groups using the t test, and the chi-square test was performed to examine the distribution of gender. The relationship between the baseline CAT score and functional evaluation was evaluated by Spearman's correlation coefficient. The Wilcoxon test was used to compare the CAT scores between baseline and re-evaluation in each group. If the patients were evaluated with the CAT more than twice, the last evaluation was adopted as the re-evaluation in the study. Comparison between the evaluations of pulmonary function was performed with the paired $t$ test. Results were considered significant at $\mathrm{p}<0.05$. SAS JMP version 11 software was used for analysis.

\section{Results}

The baseline demographic parameters and disease distribution are summarized in Table 1 . FVC and $\mathrm{D}_{\mathrm{LCO}}$ were significantly more

\begin{tabular}{|c|c|c|c|}
\hline Parameters & Early group $(n=21)$ & $\begin{array}{l}\text { Late group } \\
(n=35)\end{array}$ & $\mathbf{P}$ \\
\hline Gender $(\mathrm{f} / \mathrm{m})(\mathrm{n})$ & $12 / 9$ & $26 / 9$ & 0.24 \\
\hline Age (years) & $55 \pm 14$ & $62 \pm 12$ & 0.058 \\
\hline Height $(\mathrm{cm})$ & $162 \pm 8$ & $155 \pm 8$ & 0.003 \\
\hline Weight (kg) & $56 \pm 9$ & $51 \pm 10$ & 0.09 \\
\hline Duration of disease (years) & $1.4 \pm 1.3$ & $12.5 \pm 8.0$ & $<0.001$ \\
\hline $\begin{array}{l}\text { Interval of evaluation } \\
\text { (months) }\end{array}$ & $21 \pm 13$ & $20 \pm 11$ & 0.80 \\
\hline Disease $(\mathrm{n})$ & & & NA \\
\hline Systemic sclerosis & 8 & 20 & \\
\hline $\begin{array}{l}\text { Polymyositis/ } \\
\text { dermatomyositis }\end{array}$ & 8 & 7 & \\
\hline Rheumatoid arthritis & 0 & 3 & \\
\hline Overlap syndrome & 0 & 1 & \\
\hline $\begin{array}{l}\text { Idiopathic interstitial } \\
\text { pneumonia }\end{array}$ & 5 & 4 & \\
\hline FVC (\% pred $)$ & $94 \pm 20$ & $73 \pm 21$ & 0.001 \\
\hline $\mathrm{D}_{\mathrm{LCO}}(\%$ pred $)$ & $60 \pm 23$ & $40 \pm 15$ & 0.006 \\
\hline 6MWT distance (meters) & $488 \pm 145$ & $411 \pm 121$ & 0.11 \\
\hline \multicolumn{4}{|c|}{$\begin{array}{l}\text { Data are presented as mean } \pm \text { SD, except for numerical numbers. FVC: Forced } \\
\text { Vital Capacity; } D_{\text {LCo: }} \text { Diffusion capacity of the lung for carbon monoxide ( } \% \\
\text { predicted); } 6 \mathrm{MWT} \text { : six-minute walk test. }\end{array}$} \\
\hline
\end{tabular}

Table 1: Comparison of clinical characteristics between groups at baseline. impaired in the late group than in the early group ( $\mathrm{p}=0.001$ and 0.006 , respectively), although there was no difference in the $6 \mathrm{MWT}$ distance between the two groups $(\mathrm{p}=0.11)$. The intervals of evaluation in the two groups were similar ( 21 and 20 months on average, $\mathrm{p}=0.80$ ). FVC was correlated with the CAT score in all subjects at baseline, but no difference was found when separated by group (Table 2 ). $\mathrm{D}_{\text {LCO }}$ and the $6 \mathrm{MWT}$ distance in both groups were negatively correlated with the CAT score at baseline.

The CAT score in the early group significantly decreased, demonstrating that the quality of life improved from the baseline after an interval of 21 months on average (Figure 1). However, the FVC in the early group $(\mathrm{n}=13)$ did not change, but $\mathrm{D}_{\text {LCO }}$ decreased (Table 3 ).

\begin{tabular}{|c|c|c|}
\hline Parameters & $\rho$ & $\mathbf{P}$ \\
\hline \multicolumn{3}{|l|}{ FVC (\% pred) } \\
\hline All subjects & -0.28 & 0.044 \\
\hline Early group & -0.43 & 0.065 \\
\hline Late group & -0.26 & 0.16 \\
\hline \multicolumn{3}{|l|}{$D_{\text {Lco }}(\%$ pred $)$} \\
\hline All subjects & -0.47 & 0.001 \\
\hline Early group & -0.51 & 0.046 \\
\hline Late group & -0.46 & 0.02 \\
\hline \multicolumn{3}{|c|}{ 6MWT distance (meter) } \\
\hline All subjects & -0.63 & $<0.001$ \\
\hline Early group & -0.63 & 0.02 \\
\hline Late group & -0.59 & 0.002 \\
\hline
\end{tabular}

Table 2: Relation between the CAT score and functional evaluation at baseline.

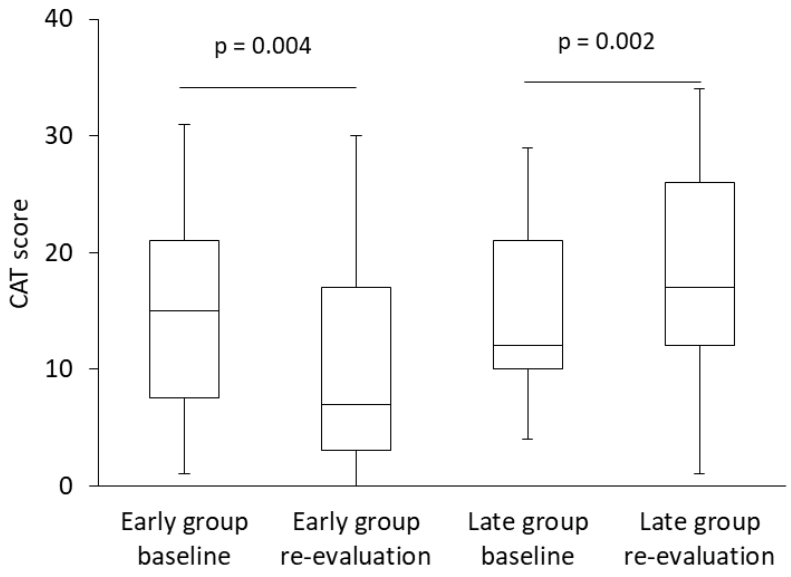

Figure 1: Longitudinal change in the CAT. Boxes show interquartile ranges, whiskers indicate lowest and highest values and horizontal lines represent medians.

\begin{tabular}{|l|l|l|l|}
\hline Parameters & Baseline & Re-evaluation & P \\
\hline FVC (\% pred) & $89 \pm 20$ & $82 \pm 25$ & 0.07 \\
\hline Early group & $69 \pm 20$ & $65 \pm 22$ & 0.03 \\
\hline Late group & \multicolumn{3}{l|}{} \\
\hline $\mathbf{D}_{\text {Lco }}$ (\% pred) & $63 \pm 23$ & $49 \pm 21$ & 0.008 \\
\hline Early group & $37 \pm 10$ & $32 \pm 11$ & 0.01 \\
\hline Late group &
\end{tabular}

Data are presented as mean \pm SD. Pulmonary function was repeatedly evaluated for 13 subjects in the early group and 21 in the late group. FVC: forced vital capacity; $D_{\text {Lco }}$ : Diffusion capacity of the lung for carbon monoxide (\% predicted).

Table 3: Longitudinal change in pulmonary function. 
Additionally, the CAT score worsened in only 2 of the 13 subjects. The pulmonary function in the late group declined during the interval, and the CAT score in the late group increased.

\section{Discussion}

The baseline CAT score in the two groups was correlated with $6 \mathrm{MWT}$ distance, which suggested that the quality of life for interstitial lung disease may be reflected by the exercise capacity throughout disease progression. Pulmonary function, especially $\mathrm{D}_{\mathrm{LCO}}$, was also correlated with the CAT score. A correlation between FVC and the CAT score was also observed in all subjects. Previous studies on interstitial lung disease reported the relationship between quality of life and values on pulmonary function tests or the 6MWT $[2,11,12]$, which supported our results. However, correlations between FVC and the CAT score were not seen in subgroups. Recent findings demonstrated that quality of life was not consistent with pulmonary function tests in subjects with interstitial lung disease $[5,13]$. This discordance was likely because of fatigue and deconditioning due to dyspnea and cough, or subjects' reduced awareness of deterioration in actual pulmonary function. As these studies, including our analysis at baseline, were cross-sectional, the relationship found here may represent the rough clinical course of interstitial lung disease.

Longitudinal studies reported that FVC was improved by treatment with cyclophosphamide in systemic sclerosis subjects, but only in the limited subjects who responded to the therapy, i.e., subjects with quickly declining FVC $[14,15]$. However, the positive effects only lasted for several months after stopping therapy [16]. Regarding idiopathic interstitial pneumonia, clinical progression is heterogeneous depending on the classified disease and acute exacerbation [17]. In subjects with idiopathic pulmonary fibrosis, it was reported that medication with pirfenidone demonstrated a relatively slower decline in FVC and $6 \mathrm{MWT}$ distance, but that the relationship between treatment and symptoms was less clear [18].

Moreover, the combination of medication and pulmonary rehabilitation was generally recommended to improve symptoms and quality of life for subjects with idiopathic pulmonary fibrosis [19]. Randomized controlled trials reported that pulmonary rehabilitation simultaneously improved 6MWT distance and quality of life without improvement in pulmonary function, but the benefits were not sustained for six months $[6,20]$, or were poorer than benefits observed for chronic obstructive pulmonary disease [21]. Therefore, according to the paradigm shift, palliative care methods were addressed for all stages of chronic respiratory disease. For example, structured communication between healthcare professionals and patients was vital to ensure the best possible support and treatment $[5,22]$.

The CAT score in the early group improved, but that in the late group declined in this study. As the standard clinical approach in our facility, we introduced pulmonary rehabilitation under the supervision of therapists to the subjects with interstitial lung disease if they exhibited low exercise capacity (approximately under $400 \mathrm{~m}$ in 6MWT distance) or exercise induced hypoxia $\left(<90 \% \mathrm{SpO}_{2}\right)$ [23]. Subsequently, the subjects were encouraged to continue the exercise and their performance was checked when they visited for regular medical examinations. Such an intervention may support the improvement in the CAT score to some extent in the early group, which had deterioration in pulmonary function. On the other hand, as the subjects in the late group had the disease for five years or more, pulmonary function and 6MWT distance were poorer compared with the early group. The results suggested effective strategies for quality of life for subjects in the late group to be considerably limited because they have likely already received almost all treatments during the progression of disease.

There was no study on the longitudinal change in quality of life for interstitial lung disease, and most studies were conducted crosssectionally. Palliative care is performed to relieve not only dyspnea, but also anxiety and depression, which are highly associated with dyspnea in interstitial lung disease [24]. The CAT has eight items, including items regarding confidence in leaving home and energy, which are related with anxiety and depression. Previously, Jones et al. [25] examined the reliability of the simple sum of the subject's responses to the items, but not each item separately in the CAT. Therefore, we did not analyze the change in the score for each item. Further research should focus on the psychological status during progression.

There were some limitations in this study. We examined subjects at a single facility with a short observation period for each subject because of the available period of the CAT. We examined the changes in the CAT scores in the two groups according to the duration of disease, but it is unclear if the five-year separation was adequate. Long term followup data are required to clarify the time point at which the quality of life for interstitial lung disease worsens.

\section{Conclusion}

In conclusion, the quality of life evaluated by the CAT improved within five years from disease onset, but it declined afterward with disease progression. The difference may be due to the decrease in pulmonary function or exercise capacity regardless of available treatments, especially worsening exercise capacity. Palliative care may be more important for such subjects.

\section{Acknowledgement}

This work was supported by JSPS KAKENHI Grant Number JP17K01450.

\section{References}

1. Jones PW, Harding G, Berry P, Wiklund I, Chen WH, et al. (2009) Development and first validation of the COPD Assessment Test. Eur Resir J 34: 648-654.

2. Nagata K, Tomii K, Otsuka K, Tachikawa R, Otsuka K, et al. (2012) Evaluation of the chronic obstructive pulmonary disease assessment test for measurement of health-related quality of life in patients with interstitial lung disease. Respirology 17: $506-512$

3. Someya F, Nakagawa T, Mugii N (2016) The COPD sssessment test as a prognostic marker in interstitial lung disease. Clin Med Insights Circ Respir Pulm Med 10: 27-31.

4. Zamora AC, Hoskote SS, Abascal-Bolado B, White D, Cox CW, et al. (2016) Clinical features and outcomes of interstitial lung disease in anti-Jo-1 positive antisynthetase syndrome. Respir Med 118: 39-45.

5. Garibaldi BT, Danoff SK (2016) Invited review series: Idiopathic interstitia pneumonia-part 3: General management issues: Symptom-based management of the idiopathic interstitial pneumonia. Respirology 21: 1357-1365.

6. Holland AE, Hill CJ, Conron M, Munro P, McDonald CF (2008) Short term improvement in exercise capacity and symptoms following exercise training in interstitial lung disease. Thorax 63: 549-554.

7. Kozu R, Jenkins S, Senjyu H (2011) Effect of disability level on response to pulmonary rehabilitation in patients with idiopathic pulmonary fibrosis. Respirology 16: 1196-1202.

8. Ferreira A, Garvey C, Connors GL, Hilling L, Rigler J, et al. (2009) Pulmonary rehabilitation in interstitial lung disease. Chest 135: 442-447.

9. Huppmann P, Sczepanski B, Boensch M, Winterkamp S, chonheit-Kenn U, et al. (2013) Effects of inpatient pulmonary rehabilitation in patients with interstitial lung disease. Eur Respir J 42:444-453.

10. Tsuda T, Suematsu R, Kamohara K, Kurose M, Arakawa I, et al. (2012) Development of the Japanese version of the COPD Assessment Test. Respir Investig 50: 34-39.

11. Swigris JJ, Wilson SR, Green KE, Sprunger DB, Brown KK, et al. (2010) 
Citation: Someya F, Nakagawa T, Mugii N (2017) Characteristics for Quality of Life during the Clinical Course of Interstitial Lung Disease. J Pulm Respir Med 7: 427. doi: 10.4172/2161-105X.1000427

Development of the ATAQ-IPF: A tool to assess quality of life in IPF. Health Qual Life Outcomes 8: 77.

12. Chang JA, Curtis R, Patrick DL, Raghu G (1999) Assessment of health-related quality of life in patients with interstitial lung disease. Chest 116: 1175-1182.

13. Lumetti F, Barone L, Alfieri C, Silva M, Serra V, et al. (2015) Quality of life and functional disability in patients with interstitial lung disease related to systemic sclerosis. Acta Biomed 86: 142-148.

14. Man A, Davidyock T, Ferguson LT, leong M, Zhang Y, et al. (2015) Changes in forced vital capacity over time in systemic sclerosis: application of group-based trajectory modelling. Rheumatology 54: 1464-1471.

15. Iudici M, Moroncini G, Cipriani P, Giacomelli R, Gabrielli A, et al. (2015) Where are we going in the management of interstitial lung disease in patients with systemic sclerosis? Autoimmun Rev 14: 575-578.

16. Tashkin DP, Elashoff R, Clements PJ, Roth MD, Furst DE, et al. (2007) Effect of 1-year treatment with cyclophspahmide on outcome at 2 years in scleroderma lung disease. Am J Respir Crit Care Med 176: 1026-1034.

17. Travis WD, Costabel U, Hansell DM, King Jr TE, Lynch DA, et al. (2013) An official American Thoracic Society/ European Respiratory Society statement: update of the international multidisciplinary classification of the idiopathic interstitial pneumonias. Am J Respir Crit Care Med 188: 737-748.

18. King Jr TE, Bradford WZ, Castro-Bernardini S, Fagan EA, Glaspole I, et al (2014) A phase 3 trial of pirfenidone in patients with idiopathic pulmonary fibrosis. N Engl J Med 370: 2083-2092.
19. Bajwah S, Ross JR, Peacock JL, Higginson IJ, Wells AU, et al. (2013) Interventions to improve symptoms and quality of life of patients with fibrotic interstitial lung disease: A systematic review of the literature. Thorax 68: 867879

20. Nishiyama O, Kondoh Y, Kimura T, Kato K, Kataoka K, et al. (2008) Effects of pulmonary rehabilitation in patients with idiopathic pulmonary fibrosis. Respirology 13: 394-399.

21. Kozu R, Senjyu H, Jenkins SC, Mukae H, Sakamoto N, et al. (2011) Differences in response to pulmonary rehabilitation in idiopathic pulmonary fibrosis and chronic obstructive pulmonary disease. Respiration 81: 196-205.

22. Wuyts WA, Peccatori FA, Russell AM (2014) Patients-centered management in idiopathic pulmonary fibrosis: similar themes in three communication models. Eur Respir Rev 23: 231-238.

23. Mugii N, Someya F, Hasegawa M (2011) Reduced hypoxia risk in a systemic sclerosis patient with interstitial lung disease after long-term pulmonary rehabilitation. Clin Med Insights Case Rep 4: 53-56.

24. Ryerson CJ, Berkeley J, Carrieri-KohIman VL, Pantilat SZ, Landefeld CS, et al. (2011) Depression and functional status are strongly associated with dyspnea in interstitial lung disease. Chest 139: 609-616.

25. Jones PW, Tabberer M, Chen WH (2011) Creating scenarios of the impact of copd and their relationship to copd assessment test (CAT ${ }^{\mathrm{TM}}$ ) scores. BMC Pulm Med 11: 42. 